\title{
The Impact of Policy Changes on Milk and Beverage Consumption of Texas WIC Children
}

\section{Ariun Ishdorj and Oral Capps, Jr.}

\begin{abstract}
Major changes in the Special Supplemental Nutrition Program for Women, Infants, and Children (WIC) food packages that were implemented in 2009 included reductions in the amount of milk and $100 \%$ juices, as well as the removal of whole milk from food packages. In analyzing the effect of these changes on the beverage consumption of Texas WIC children ages two to four, we found a significant decrease in the amount of whole milk consumed, and this decrease was partially offset by the increase in the amount of lower-fat milks consumed. Intakes of both desirable and undesirable nutrients from milk were decreased.
\end{abstract}

Key Words: beverages, juice, milk, nutrients, ordered probit model, Texas, WIC

Improving the nutritional well-being of the low-income population is one of the primary objectives of United States Department of Agriculture's (USDA) fifteen domestic food assistance programs. The third largest of these, in terms of total expenditure, is the Special Supplemental Nutrition Assistance Program for Women, Infants, and Children (WIC), which targets low-income pregnant, breastfeeding, and postpartum women, infants, and children up to age five. The WIC program provides supplemental foods, nutrition education, breastfeeding support, and referrals to health and social services for its participants. To expand the selection of foods the program offered and help combat the problem of obesity, the WIC food packages were revised in 2007, and the changes were implemented in 2009. The revised food packages were designed to contribute to an overall dietary pattern that is consistent with

Ariun Ishdorj is an associate professor in the Department of Agricultural Economics at Texas A\&M University. Oral Capps, Jr., is a regents professor and executive professor, and co-director of the Agribusiness Food and Consumer Economics Research Center in the Department of Agricultural Economics at Texas A\&M University. Correspondence: Ariun Ishdorj - AGLS 345 - Department of Agricultural Economics - Texas A\&M University - College Station TX 77843-2124 - Phone: 979.845-6322-Email aishdorj@tamu.edu.

This research was funded through a Research Innovation and Development Grant in Economics (RIDGE) Center for Targeted Studies award from the U.S. Department of Agriculture's Economic Research Service, administered through the Southern Rural Development Center at Purdue University under award No. 8000056289. The open access publishing fees for this article have been covered by the Texas A\&M University Open Access to Knowledge Fund (OAKFund), supported by the University Libraries and the Office of the Vice President for Research.

The views expressed in this publication are those of the authors and do not necessarily reflect the policies or views of any sponsoring agencies.

Agricultural and Resource Economics Review 46/3 (December 2017) 421-442

(C) The Author(s) 2017. This is an Open Access article, distributed under the terms of the Creative

Commons Attribution licence (http://creativecommons.org/licenses/by/4.0/), which permits unrestricted re-use, distribution, and reproduction in any medium, provided the original work is properly cited. 
the Dietary Guidelines for Americans as well as to ensure that foods are readily acceptable, widely available, and commonly consumed by the target population (Institute of Medicine 2006, USDA 2007).

Some of the major changes in the revised WIC food packages were the reduction in the total amount of milk and the removal of whole milk from food packages offered to women and children of ages two through four years (Table 1). Texas allowed the purchase of $2 \%$ milk after the changes in WIC food packages for children ages two through four. However, effective October 1,2014 , only $1 \%, 1 / 2 \%$ and fat-free milks were allowed. Furthermore, $100 \%$ juices continued to be included in the food packages but were offered in reduced amounts. Juice allowances for children were reduced by more than half (from 288 ounces to 128 ounces per month). Although it is well known that some of the most commonly consumed beverages have a high caloric content and may contribute to the current obesity epidemic, relatively few studies have examined dietary patterns of children with regard to beverage consumption. Beverages contribute a notable amount of calories to the diet of individuals. It is critical to understand the descriptive patterns of beverage consumption of children in order to help design intervention strategies to promote healthier beverage consumption in specific higher-risk subgroups.

The objective of this paper is to examine the effect of policy changes to the WIC food packages on the milk and beverage consumption of children. Specifically, we center our attention on whole, 2\%, 1\%, and skim milk, $100 \%$ juices and other sugar- and artificially sweetened beverages consumed by Texas WIC-participating children of ages two through four years. This study contributes to the existing literature by analyzing data from before and after revision of WIC food packages. Using data from the Texas Food and Nutrition

\section{Table 1. Maximum Monthly Allowances of Milk and Juice for WIC Children} Ages 2-4*

\begin{tabular}{|c|c|c|}
\hline & Before & After \\
\hline $\begin{array}{l}\text { Juices, single } \\
\text { strength }\end{array}$ & $\begin{array}{l}\text { Maximum juice amounts ranged } \\
\text { from } 192 \text { to } 336 \mathrm{oz} \text {. per month }\end{array}$ & $\begin{array}{l}\text { Reduced maximum } \\
\text { amount to } 128 \mathrm{oz} .\end{array}$ \\
\hline Milk & $\begin{array}{l}\text { No restrictions on milk fat content. } \\
\text { Maximum milk prescriptions } \\
\text { ranged from 24-28 quarts of } \\
\text { milk per month. Cheese could be } \\
\text { substituted for milk at a rate of } \\
\text { one pound per three quarts; } \\
\text { cheese could replace a total of } \\
12 \text { quarts of milk. }\end{array}$ & $\begin{array}{l}\text { Children age two and older } \\
\text { receive reduced-fat milk; } \\
\text { whole milk provided to } \\
\text { children one years of } \\
\text { age. Maximum milk } \\
\text { prescriptions reduced to } \\
\text { provide } 16 \text { quarts for } \\
\text { children }\end{array}$ \\
\hline
\end{tabular}

Source: *Adapted by the authors from Table 2, U.S. Department of Agriculture, Food and Nutrition Services, Special Supplemental Nutrition Program for Women, Infants and Children, (WIC): Revisions in the WIC Food Packages; Interim Rule. 7 CFR Part 246, 68966-99032. Downloaded from: http:// www.fns.usda.gov/wic/regspublished/foodpackages-interimrule.htm. 
Survey for WIC (TEXFAN), we analyzed the effect of the removal of whole milk as well as the reduction in the total amount of milk and $100 \%$ juices provided by WIC on the type and on the amount of milk consumed and nutrient intake (calories, total fat, saturated fat, cholesterol, sodium, protein, calcium, potassium, vitamin A, and vitamin D) from milk by WIC children. We also investigated if the aforementioned changes in WIC affected the consumption frequency of $100 \%$ juices, and sugar-sweetened and artificially sweetened beverages consumed by WIC children.

Why Texas? Today, the WIC program serves a culturally diverse population with a wide range of traditional food preferences. In this regard, Texas is one of the most culturally, ethnically, and racially diverse states in the United States. As the second largest state in the nation, with a population of over 25 million, the size and scope of Texas poses unique challenges due to the rapidly changing demographics and cultural diversity. Hispanics are the fastest-growing population in Texas. In 2011, 38.1 percent of Texans were Hispanic, in contrast to 32 percent in 2000. Texas is one of the most urban states in the nation, with three of the top ten largest cities and the majority of its people concentrated in only 20 of the 254 counties in the state. Texas still has the nation's largest rural population, with more than 20 percent of its population living in rural areas. Texas provides services to over 10 percent of all WIC participants, the second largest WIC program with respect to participants after California (USDA 2011), with the majority of its participants being Hispanic. About 10 percent of the Texas population resides within 62 miles of the United States-Mexico border, and 84 percent of those living in border regions are Hispanic. Hispanic households near the United States-Mexico border are primarily poor and face greater vulnerability to food security, overweight/obesity and poor nutritional health.

In 2014, the Food and Nutrition Board convened a committee to review and assess the nutrition status and food and nutritional needs of the WIC-eligible population, as well as the impact of the 2009 regulation and food package revisions. The committee recommended new revisions to WIC food packages. These recommendations will take into account the health and cultural needs of the WIC participant population. In this regard, the findings of this paper provide an opportunity to examine patterns, associations, and other relevant information related to beverage choices for children participating in WIC and add to the knowledge of understanding the effects of the WIC food package revisions on its participants.

\section{Background and Related Research on WIC}

WIC began as a pilot program in 1972 and became permanent in 1974. Over the next few decades, WIC influenced the lives of millions of its participants and became one of the largest food assistance programs targeting the low-income population. 
Much of the existing literature devoted to WIC has focused on food and nutrient intake as well as the health outcome of its target population (Rose, Habicht, and Devaney 1998, Burstein et al. 2000, Oliveira and Gundersen 2000, Ponza et al. 2004, Siega-Riz et al. 2004, Oliveira and Chandran 2005, Ishdorj, Jensen, and Tobias 2008, Yen 2010). A handful of these studies explored these issues using large national surveys such as the National Health and Nutrition Examination Survey (NHANES) (Cole 2001, Lin 2005, Ver Ploeg 2009), and the Continuing Survey of Food Intakes by Individuals (CSFII) (Rose, Habicht, and Devaney 1998, Oliveira and Gundersen 2000, Siega-Riz et al. 2004, Oliveira and Chandran 2005, Ishdorj, Jensen, and Tobias 2008, Yen 2010).

The majority of work focusing on food and nutrient intake of children has, with few exceptions, found that the WIC program performs as desired and that the children receiving targeted food assistance are consuming more WICapproved foods than nonparticipants. Among the studies that considered the WIC program, there were several that looked at the food consumption of WIC participants using regional or state-level data (Dennison, Erb, and Jenkins 2001, Herman et al. 2008, Black et al. 2009). Dennison, Erb, and Jenkins (2001) examined the types of milk that were consumed by children participating in the New York State WIC program before the changes in WIC food packages and found that 75 percent of WIC-participating children consumed whole milk, while only 6.9 percent consumed exclusively $1 \%$ and/ or skim milk. They also found that children tended to drink the same type of milk as other members of the household.

To our knowledge there are only a handful of studies that have looked at the effect of the revised WIC food packages on WIC participants' food consumption, and the majority of them used data that are either regional or a subsample of the population (Whaley et al. 2012, Chiasson et al. 2013, Ishdorj and Capps 2013, Odoms-Young et al. 2014, Kong et al. 2014). A number of studies looked at the availability of WIC-approved foods in WIC-certified and nonWIC stores and at food purchases in WIC households (Andreyeva 2012, Andreyeva et al. 2012, Ayla et al. 2012, Hillier et al. 2012, Zenk et al. 2012, Andreyeva et al. 2014). With respect to the effect of revisions in WIC food packages on milk and beverage consumption of participants, Whaley et al. (2012) found that the consumption of whole milk decreased and the consumption of lower-fat milk increased for California WIC participants after the changes to the food packages. Kong et al. (2014) and Chiasson et al. (2013) found similar results for WIC participating children in Chicago, IL and the New York state, respectively. Studies that used scanner data from a New England supermarket chain before and after implementation of the revised WIC packages found that total milk purchases of WIC households decreased by 14 percent, whole milk by 50 percent (Andreyeva et al. 2014) and juice by 44 percent (Andreyeva et al. 2013). The reduction in juice purchases was only partly compensated for by an increase of 14 percent using other nonWIC funds, whereas milk purchases with non-WIC funds remained almost 
flat. Results of the existing literature on the WIC program highlight the importance of how including specific foods in the WIC food packages may influence a change in purchases and consumption of specific foods and beverages of program participants. Our paper contributes to this literature by conducting the analysis of milk and beverage consumption of Texas WIC children ages two through four years, both before and after implementing the revised WIC food packages.

\section{Data and Methods}

We conducted a secondary analysis of data from two similar cross-sectional datasets of children before the programmatic changes, the Texas Food and Nutrition (TEXFAN) 2008-2009 survey, and the other after the programmatic changes, TEXFAN 2010-2011, more than six months after the changes. The TEXFAN data were collected under the auspices of the Institute for Obesity Research and Program Evaluation at Texas A\&M University in collaboration with Texas WIC and USDA (McKyer et al. 2011, Ettienne-Gittens et al. 2013). To establish validity of the survey, all the iterations of TEXFAN questionnaire were reviewed by Texas WIC-registered dieticians and by a panel of experts from the University of Texas "Nutrition Education Team," the USDA Food and Nutrition Service Staff, and Texas Department of State Health Services Nutrition Education consultants and experts, who were experienced in survey design and instrument development for the WIC population. All 73 Texas WIC local agencies participated in the survey. About 7,500 questionnaires for women, children, and infants were distributed to local agencies, both before and after the changes in WIC, and the response rate was about 93 percent for both periods. Each local WIC agency received at least 50 questionnaires, with increases made for local agencies serving more WIC participants (McKyer et al. 2011). Local agency directors then determined which of their clinics to include in the study and how many questionnaires to send. Local WIC clinic staff administered the surveys using samples of WIC participants who attended WIC clinics during the data collection periods. WIC participants were recruited to complete the questionnaires during their scheduled nutrition education classes offered by WIC. Class enrollees were asked if they were willing to participate in the study in lieu of their regular educational classes. All participants were either pregnant or postpartum, and/or were caregivers of an infant under one year of age, and/or had a child under five years of age (McKyer 2011). The respondents completed separate questionnaires for women, infants, and children who participated in WIC, ${ }^{1}$ with both English and Spanish versions available to them. Responses from

\footnotetext{
1 Because it is possible that more than one individual from the household received WIC benefits, the respondents were asked to complete the survey for each household member that participate in WIC.
} 
the children's questionnaire were used in the current research, because we were interested in beverage consumption of WIC-participating children ages two through four. Almost 100 percent of the questionnaires in our children's sample were completed by the child's caregiver.

The variables of interest in our study were amount of milk, the type of milk most often consumed, and the frequency of $100 \%$ juices and sugarsweetened and artificially sweetened beverages consumed. Here $100 \%$ juices include orange, apple, or tomato varieties; sugar-sweetened drinks include Kool-Aid, soda, cola, sports drinks, or sugar-sweetened tea; and artificially sweetened drinks include diet soda, diet cola, or Crystal Light. No information was provided on the frequency of milk consumed and the amounts of beverages consumed, except for milk.

Sociodemographic information on gender and age of a child, language spoken at home, ethnicity/race, age, and education level of caregivers, presence of other WIC children, and the zip code of residence were available from the data. No information was provided on household income or size. Rural and urban classifications using the self-reported zip code were created with specific attention paid to those children who lived in households close to the United States-Mexico border.

Econometric analysis, based on the use of the TEXFAN data, allowed us to identify and assess the factors associated with the choices of milk types and the frequency of other beverages consumed. The dependent variable is equal to one if the WIC-participating child consumed whole milk most often, two if $2 \%$ fat milk is mostly chosen, and three if $1 \%$ fat or skim is mostly chosen ( $1=$ whole milk; $2=2 \%$ milk; and $3=1 \%$ or skim milk).

The data provide information on the frequency of $100 \%$ juice, sugarsweetened and artificially sweetened beverage consumption per day and per week (never or less than once per week, 1 to 3 times per week, 4 to 6 times per week, 1 time per day, 2 times per day, 3 times per day, and 4 or more times per day). Therefore, the dependent variables for beverages were measured on a scale that is discrete and ordinal. As a result, ordered probit models were used in the analysis of milk type and frequency of $100 \%$ juices, sugar- and artificially sweetened beverage consumption.

The ordered probit model is based on the following implicit function:

$$
y_{i}^{*}=x_{i}^{\prime} \beta+u_{i}
$$

In the above equation, $y_{i}^{*}$ is the unobserved choice of individual $i, \beta$ is a vector of parameters, $x_{i}^{\prime}$ is a matrix of explanatory variables, and $u_{i}$ is the error term. In the ordered probit model, $u_{i}$ has the standard normal distribution. Following Cameron and Trivedi (2009) and Greene (2008), an $m$-alternative ordered model has $y_{i}=j$ if $a_{j-1}<y_{i}^{*}<a_{j}$ where $\alpha_{0}=-\infty$ and $\alpha_{m}=\infty$. The probability that $y_{i}$ will be classified in a particular category $j$ is: 


$$
\begin{aligned}
\operatorname{Pr}\left[y_{i}\right. & =j]=\operatorname{Pr}\left[\alpha_{j-1}<y_{i}^{*}<\alpha_{j}\right] \\
& =\operatorname{Pr}\left[\alpha_{j-1}<x_{i}^{\prime} \beta+u_{i} \leq \alpha_{j}\right] \\
& =\operatorname{Pr}\left[\alpha_{j-1}-x_{i}^{\prime} \beta<u_{i} \leq \alpha_{j}-x_{i}^{\prime} \beta\right] \\
& =F\left(\alpha_{j}-x_{i}^{\prime} \beta\right)-F\left(\alpha_{j-1}-x_{i}^{\prime} \beta\right)
\end{aligned}
$$

where $F$ is the cumulative distribution function for standard normally distributed errors, $u_{i}$. The regression parameters $\beta$ and the $(m-1)$ threshold parameters $\alpha_{1}, \ldots, \alpha_{m-1}$ will be obtained by maximum likelihood methods. To interpret the sign and magnitude of the effect of the explanatory variables on the variables of interest, the marginal effects were obtained as follows:

$$
\frac{\partial \operatorname{Pr}\left[y_{i}=j\right]}{\partial x_{i}}=\left\{F^{\prime}\left(\alpha_{j-1}-x_{i}^{\prime} \beta\right)-F^{\prime}\left(\alpha_{j}-x_{i}^{\prime} \beta\right)\right\} \beta .
$$

All calculations of descriptive statistics, parameter estimates of ordered probit model, marginal effects, and their associated marginal effects were done using Stata 14. To discern whether statistically significant differences exist in milk choices made by WIC participants before and after programmatic changes, we pooled the data and estimated the ordered probit model. With the pooled dataset, the set of explanatory variables include a dummy variable equal to one corresponding to observations after the change in the WIC program and equal to zero, corresponding to observations before the change in the WIC program. Consequently, based on the significance of the estimated coefficient associated with this dummy variable, we were in a position to identify and assess differences in milk and other beverage choices made by WIC participants.

\section{Results}

Our final sample consists of 2,782 observations of Texas WIC-participating children ages two through four, with 1,339 before the WIC food package revisions and 1,443 observations after the WIC food package revisions. The sample size of rural WIC children $(n=593)$ was smaller than the sample size of urban WIC children $(\mathrm{n}=2,189)$.

Table 2 provides descriptive statistics, for the total sample and by rural and urban, of independent variables used in the analyses, both before and after the changes in WIC food packages. The distributions for before and after samples of explanatory variables used in the analysis were very similar. The average caregiver's age was 29. A little over 20 percent of caregivers in our sample were employed full time, and over 60 percent were not employed. More than a third of caregivers had less than a high school education, and about 3 percent had college or graduate degrees. Consequently, roughly 60 percent of caregivers had a high school degree or higher. About 28 percent of caregivers 
Table 2. Sample Mean Values of Explanatory Variables, Texas WIC Children Ages 2-4, by Urbanicity (\%)

\begin{tabular}{|c|c|c|c|c|c|c|}
\hline & \multicolumn{2}{|c|}{ Total } & \multicolumn{2}{|c|}{ Urban } & \multicolumn{2}{|c|}{ Rural } \\
\hline & Before & After & Before & After & Before & After \\
\hline \multicolumn{7}{|l|}{ Child } \\
\hline Female & 47.1 & 48.8 & 47.2 & 48.1 & 47.0 & 51.3 \\
\hline Two years old & 40.1 & 39.2 & 40.9 & 39.0 & 37.0 & 39.7 \\
\hline Three years old & 36.2 & 36.9 & 36.1 & 36.4 & 36.7 & 38.8 \\
\hline Four years old & 23.7 & 23.9 & 23.0 & 24.6 & 26.3 & 21.5 \\
\hline Presence of other WIC children & 51.0 & 48.0 & 49.0 & 47.0 & 54.0 & 49.0 \\
\hline \multicolumn{7}{|l|}{ Caregiver } \\
\hline Less than high school & 36.8 & 35.2 & 39.1 & 36.1 & 28.1 & 32.1 \\
\hline High school or GED & 33.9 & 34.8 & 32.9 & 34.7 & 37.7 & 34.9 \\
\hline Some college & 26.7 & 27.2 & 25.2 & 26.3 & 32.4 & 30.1 \\
\hline College or Graduate & 2.5 & 2.8 & 2.7 & 2.8 & 1.8 & 2.9 \\
\hline Employed full time & 23.7 & 21.7 & 22.2 & 20.8 & 29.5 & 25.0 \\
\hline Employed part time & 14.4 & 15.9 & 14.0 & 15.4 & 16.0 & 17.9 \\
\hline Not employed & 61.8 & 62.4 & 63.8 & 63.8 & 54.4 & 57.1 \\
\hline Hispanic & 67.6 & 69.2 & 70.9 & 71.1 & 55.2 & 62.2 \\
\hline White & 19.0 & 16.3 & 15.2 & 13.5 & 33.1 & 26.3 \\
\hline Black & 7.7 & 10.6 & 8.2 & 11.0 & 5.7 & 9.3 \\
\hline Other race & 5.8 & 4.0 & 5.7 & 4.4 & 6.0 & 2.2 \\
\hline Speaks English & 45.8 & 43.7 & 41.7 & 40.5 & 61.2 & 55.4 \\
\hline Speaks Spanish & 27.7 & 27.9 & 27.0 & 28.0 & 30.2 & 27.2 \\
\hline Speaks Spanish and English & 26.1 & 27.5 & 30.8 & 30.8 & 8.2 & 15.7 \\
\hline Speaks other languages & 0.4 & 0.9 & 0.5 & 0.7 & 0.4 & 1.6 \\
\hline Caregiver's age & 28.9 & 29.1 & 28.9 & 29.0 & 28.8 & 29.5 \\
\hline Border region & 18.4 & 18.9 & 15.9 & 17.4 & 21.4 & 20.5 \\
\hline $\mathbf{N}$ & 1339 & 1443 & 1058 & 1131 & 281 & 312 \\
\hline
\end{tabular}

reported speaking Spanish most often at home, and the same percentage reported speaking both Spanish and English most often at home. Before the changes in WIC food packages, about 39 percent of children residing in urban areas had caregivers with less than high school education compared to 28 percent for rural. More than 30 percent of caregivers reported speaking Spanish and English at home in urban areas, both before and after WIC food package revisions, compared to only 8.2 percent for before and 15.7 percent 
for after WIC food package revisions in rural areas. A higher percentage of caregivers residing in rural areas were employed (45.5 percent for before and 42.9 percent for after) compared to caregivers residing in urban areas (36.2 percent for both before and after).

For about 50 percent of the sample, a child aged two through four was the only child receiving WIC benefits in the household. About 40 percent of the households reported having an additional infant or child receiving WIC, and the rest reported having two or more additional infants or children receiving WIC, both before and after the changes in WIC food packages. Roughly a quarter of households in our sample reported having an infant receiving WIC.

The only significant difference we observed for border and nonborder regions in comparison to total sample was the percentage of Hispanic respondents. Over 90 percent of caregivers who reported living in the United StatesMexico border regions of Texas were Hispanic, and about 50 percent of all caregivers living in the border regions reported speaking both Spanish and English, and 37 percent of all caregivers living in the border regions reported speaking Spanish only. Distributions of other explanatory and dependent variables for border and nonborder regions were similar to the whole sample. ${ }^{2}$

Our findings on whole milk and lower-fat milk consumption in Texas before and after the changes in WIC food packages were consistent with findings from other studies that used data from different states and different ethnic groups. Using store-level purchase data from a New England supermarket chain, Andreyeva et al. (2014) found that WIC food package revisions led to a substantial decrease in whole milk share (from about 60 percent to 25 percent) in milk purchases for WIC households. After controlling for the household and store-level covariates, they found a significant drop of 19.5 percent in milk purchases with WIC benefits, with no significant change in milk purchases made with personal funds and other benefits cards. Using data from California WIC participants, Whaley et al. (2012) found that the number of WIC children who usually consumed whole milk decreased by 19.7 percent, and the number of children who usually consumed lower-fat milk increased by 19.5 percent following the WIC food package changes. In examining the long-term impact of food package changes on overall diet quality of WIC children in Chicago, Illinois, Kong et al. (2014) found that more children drank reduced-fat milk at 18 months following the food package changes compared to baseline. Specifically, they found that the proportion of Hispanic WIC children drinking whole milk decreased from 59 percent before the changes in WIC to 10 percent after, whereas the proportion of Hispanic children drinking reduced-fat milk increased from 55 percent to 84 percent. Our findings show a significant shift away from whole milk and towards reduced-fat milk after implementing the new food

2 These results are not included in the paper and are available from the authors on request. 
Table 3. Percent of Texas WIC Children Ages 2-4 Who Consumed Milk, by Milk Type and Average Cups of Milk Consumed per Day

\begin{tabular}{lccccccccc}
\hline & \multicolumn{3}{c}{ Total } & & \multicolumn{2}{c}{ Urban } & & \multicolumn{2}{c}{ Rural } \\
\cline { 2 - 4 } & Before & After & p-value & & Before & After & & Before & After \\
\hline Whole milk & 61.4 & 8.7 & $<0.001$ & & 61.1 & 8.3 & & 62.6 & 9.9 \\
Reduced-fat milk & 32.6 & 81.5 & $<0.001$ & & 33.2 & 81.5 & & 31.7 & 81.4 \\
Low-fat/skim milk & 5.9 & 9.8 & $<0.001$ & & 5.6 & 10.1 & & 5.7 & 8.7 \\
Cups of milk per day & 2.63 & 2.33 & $<0.01$ & & 2.62 & 2.33 & & 2.67 & 2.32 \\
N & $\mathbf{1 3 3 9}$ & $\mathbf{1 4 4 3}$ & & & $\mathbf{1 0 5 8}$ & $\mathbf{1 1 3 1}$ & & $\mathbf{2 8 1}$ & $\mathbf{3 1 2}$ \\
\hline
\end{tabular}

packages in Texas (Table 3). The total percentage of children consuming whole milk decreased from 61.4 percent to 8.7 percent, whereas the percentage of children consuming reduced-fat milk increased from 32.6 percent to 81.5 percent. About 9 percent of children in our sample reported consuming whole milk after implementation of the revision, suggesting that WIC households may have used their own funds or other non-WIC funds to purchase whole milk. Although WIC benefits are not intended for sharing, it is likely because about 50 percent of our sample reported having another infant/child receiving WIC (Table 2). It is possible that other members of WIC households, such as younger siblings, in our sample received whole milk through WIC. Thus, WIC children in our sample may be drinking whole milk provided to a younger WIC sibling. There was a significant increase in the percentage of children consuming low-fat/skim milk, from 5.9 percent in the period beforehand to 9.8 percent in the period after the changes in food packages. As shown in Table 3, the average amount of milk consumed per day decreased by 11 percent (from 2.63 cups to 2.33 cups per day) after the WIC food package revisions. The food package changes which (a) reduced the amount of milk provided, and (b) eliminated whole milk from the food packages for two- to four-year-olds might have contributed to the lower amount of milk consumed and shift towards lower-fat milks after the change. No significant differences were observed for rural and urban areas with respect to the amount of milk consumed per day. A slightly higher percentage of children consumed whole milk in rural areas compared to those located in urban areas after the changes in WIC food packages.

Using the amount of milk consumed per day (cups/day), we calculated the average nutrient intake from milk for children in our sample, both before and after the changes in WIC food packages (Table 4). We observed a significant decrease in the amount of nutrients received from milk after the WIC food package revisions, except for vitamin A. Specifically, intakes of 'undesirable' nutrients, such as calories, total fat, saturated fat, cholesterol, and sodium, decreased by 20.7 percent, 36.6 percent, 31.9 percent 22.31 percent, and 
Table 4. Nutrient intakes from milk of WIC children ages 2-4, before and after changes in WIC

\begin{tabular}{lrrrrr}
\hline & \multicolumn{2}{c}{ Total } & & \multicolumn{2}{c}{ Comparison of Before and After } \\
\cline { 2 - 3 } \cline { 5 - 6 } & Before & After & & Difference & \% change \\
\hline Calories (kcal) & 355.9 & 282.1 & & -73.8 & -20.7 \\
Total fat (g) & 17.2 & 10.9 & & -6.3 & -36.6 \\
Sat fat (g) & 10.3 & 7.0 & & -3.3 & -31.9 \\
Cholesterol (mg) & 57.5 & 44.7 & & -12.8 & -22.3 \\
Sodium (mg) & 260.5 & 233.7 & & -26.8 & -10.3 \\
Protein (g) & 20.9 & 18.8 & & -2.1 & -10.0 \\
Calcium (mg) & 737.0 & 665.2 & & -71.8 & -9.7 \\
Potassium (mg) & 936.3 & 851.2 & & -85.1 & -9.1 \\
Vitamin A (IU) & 246.4 & 302.0 & & 55.6 & 22.6 \\
Vitamin D (IU) & 266.0 & 245.2 & & -20.8 & -7.8 \\
\hline
\end{tabular}

The differences in nutrient intakes from before and after the changes in WIC were all significant at $1 \%$ level.

10.3 percent respectively, whereas intakes of 'desirable' nutrients, such as protein, calcium, potassium, and vitamin D, decreased by 10 percent, 9.7 percent, 9.1 percent, and 7.8 percent, respectively. The changes in type and amount of milk provided by WIC was motivated by a desire to reduce calories and saturated fat. Lower-fat milks are lower in 'undesirable' nutrients (USDA 2016). However, given that lower-fat milks tend to have higher amounts of 'desirable' nutrients ${ }^{3}$ than whole milk, it is not intuitively clear why intakes of 'desirable' nutrients declined, except for vitamin A. The percentage of changes in undesirable nutrients from the period before the changes in WIC packages to after were much higher than the percentage change in more desirable nutrients. Because the amount of milk consumed per day decreased by 11 percent (from 2.63 cups/day before to 2.33 cups/day after), and lower-fat milk contains lower amounts of 'undesirable' nutrients and higher amounts of 'desirable' nutrients, a shift in consumption away from whole milk toward lower-fat milk, as a result of changes in WIC foods offered, led to healthier food-consumption patterns in program participants.

With respect to consumption of beverages other than milk, we found that $100 \%$ juices were consumed more frequently per day compared to other beverages (Table 5). The frequency of consumption at ' 2 or more times per

\footnotetext{
3 For example, two-percent milk has about 26 percent more vitamin A than whole milk, only 11 percent more protein, 14 percent more calcium and 23 percent more potassium, and 21 percent less vitamin D (USDA 2016).
} 
Table 5. Frequency of $\mathbf{1 0 0 \%}$ Juices, Sugar- and Artificially Sweetened Beverages Consumed by Texas WIC Children Ages 2-4 (\% of children)

\begin{tabular}{|c|c|c|c|c|c|c|c|c|c|c|}
\hline & \multicolumn{2}{|c|}{ Never } & \multicolumn{2}{|c|}{ 1-3 times/week } & \multicolumn{2}{|c|}{ 4-6 times/week } & \multicolumn{2}{|c|}{1 time/day } & \multicolumn{2}{|c|}{2 or more times/day } \\
\hline & Before & After & Before & After & Before & After & Before & After & Before & After \\
\hline $100 \%$ juices & 2.39 & 2.01 & 22.33 & 18.09 & 16.58 & 15.11 & 17.92 & 19.75 & 40.78 & 45.05 \\
\hline Sugar-sweetened drinks & 28.94 & 26.32 & 34.65 & 34.14 & 8.68 & 8.5 & 9.08 & 11.65 & 18.65 & 19.4 \\
\hline $\begin{array}{l}\text { Artificially Sweetened } \\
\text { drinks }\end{array}$ & 48.35 & 51.85 & 22.78 & 18.28 & 4.81 & 3.21 & 4.14 & 6.28 & 19.92 & 20.38 \\
\hline
\end{tabular}


day' was greater for artificially sweetened beverages than for sugar-sweetened beverages, but not the case for ' 1 time per day' '1-3 times per week' and '4-6 times per week'. The percentage of children consuming $100 \%$ juices, sugar- and artificially sweetened beverages ' 1 time per day' and ' 2 or more times per day' increased after the changes in WIC program, whereas the percentage of children consuming these beverages '1-3 times per week' and '4-6 times per week' decreased after the changes in food packages. About 50 percent of children in our sample never consumed artificially sweetened beverages, neither before nor after the changes in WIC food packages. Frequency of consumption was higher for $100 \%$ juices than for sugar- and artificially sweetened beverages and typically increased after the food package changes. Due to limitations of our data, we could not make any definitive conclusions about the amounts of those beverages consumed. It is possible that after implementation of the package revisions, children consumed smaller quantities more frequently. Using scanner data from supermarket chain to assess juice and other beverage amounts of WIC households, Andreyeva et al. (2013) found that after the implementation of WIC food package revisions, total juice purchases decreased roughly by 23.5 percent; however, juice drink and other noncarbonated drink purchases increased by 20.9 percent and 21.3 percent, respectively.

We estimated ordered probit models using the entire sample, because no significant differences were observed from the descriptive analysis between rural and urban areas and for border and nonborder regions.

Table 6 provides the marginal effects of the estimated ordered probit model for milk types. The probability of consuming whole milk decreased by 45 percent, and the probability of consuming reduced fat milk increased by 33 percent for the period after the changes in WIC food packages compared to period beforehand. We observed that some children reported whole milk consumption in the data set corresponding to post-WIC changes, and this is possible because our measure of milk consumption also includes non-WIC milk purchased by the household. Also, sharing of WIC food benefits within the household can help explain whole milk consumption after the changes in WIC, because children in our sample may be drinking whole milk provided to a younger sibling in the household who is also in WIC. Our results show that the presence of other WIC children in the household increases the probability of consuming whole milk by 6 percent and decreases the probability of consuming $2 \%$ and lower-fat milks by 4 percent and 2 percent, respectively.

Compared to two-year-olds, three- and four-year-olds were less likely to consume whole milk and were more likely to consume reduced-fat and lowfat/skim milk. WIC allows whole milk for only infants and children up to two years of age. It is possible that some of the two-year-olds had not yet transitioned to the two-year-old packages, and were consuming whole milk from the one-year-old package; or maybe households were more likely to purchase whole milk to extend the child's transition from whole milk to lower-fat milk. Caregivers' education level had a significant effect on the type 
Table 6. Marginal Effects of Ordered Probit Model for Milk Types Most Often Consumed by Texas WIC Children Ages 2-4.

\begin{tabular}{|c|c|c|c|c|c|c|}
\hline & \multicolumn{2}{|c|}{ Whole } & \multicolumn{2}{|c|}{ Reduced fat } & \multicolumn{2}{|c|}{ Low fat/skim } \\
\hline & ME & Std & ME & Std & ME & Std \\
\hline Female & 0.011 & 0.016 & -0.008 & 0.012 & -0.003 & 0.005 \\
\hline Three years old & $-0.058^{* * *}$ & 0.019 & $0.042^{* * *}$ & 0.014 & $0.016^{* * *}$ & 0.005 \\
\hline Four years old & $-0.105^{* * *}$ & 0.021 & $0.076^{* * *}$ & 0.016 & $0.029^{* * *}$ & 0.006 \\
\hline High school or GED & -0.012 & 0.020 & 0.009 & 0.015 & 0.003 & 0.006 \\
\hline Some college & $-0.091^{* * *}$ & 0.023 & $0.066^{* * *}$ & 0.016 & $0.025^{* * *}$ & 0.006 \\
\hline College or Graduate & $-0.141^{* * *}$ & 0.052 & $0.102^{* * *}$ & 0.037 & $0.039 * * *$ & 0.014 \\
\hline Employed full time & 0.001 & 0.021 & -0.001 & 0.015 & 0.000 & 0.006 \\
\hline Employed part time & 0.014 & 0.024 & -0.010 & 0.017 & -0.004 & 0.007 \\
\hline Hispanic & -0.023 & 0.026 & 0.017 & 0.019 & 0.006 & 0.007 \\
\hline Black & $0.138^{* * *}$ & 0.034 & $-0.100^{* * *}$ & 0.025 & $-0.038^{* * *}$ & 0.010 \\
\hline Other race & -0.047 & 0.044 & 0.034 & 0.032 & 0.013 & 0.012 \\
\hline Speaks English & 0.005 & 0.023 & -0.003 & 0.017 & -0.001 & 0.007 \\
\hline Speaks Spanish & $-0.037^{*}$ & 0.023 & $0.027^{*}$ & 0.016 & $0.010^{*}$ & 0.006 \\
\hline Speaks other languages & $0.196^{*}$ & 0.106 & $-0.142^{*}$ & 0.077 & $-0.054^{*}$ & 0.030 \\
\hline Caregiver's age & $-0.001^{* *}$ & 0.001 & $0.001^{* *}$ & 0.001 & $0.000^{* *}$ & 0.000 \\
\hline Urban & -0.011 & 0.021 & 0.008 & 0.150 & 0.003 & 0.006 \\
\hline Border region & 0.005 & 0.022 & -0.004 & 0.016 & -0.001 & 0.006 \\
\hline Presence of other WIC children & $0.059 * * *$ & 0.022 & $-0.042^{* * *}$ & 0.010 & $-0.016^{* * *}$ & 0.001 \\
\hline After change in WIC & $-0.454^{* * *}$ & 0.018 & $0.328^{* * *}$ & 0.018 & $0.125^{* * *}$ & 0.008 \\
\hline
\end{tabular}

ME-marginal effect.

Std.-standard deviation associated with the marginal effect.

$* * * * *$, and ${ }^{*}$ represent significance at $1 \%, 5 \%$, and $10 \%$ levels, respectively. 
of milk most often consumed by children. Compared to caregivers with less than a high school degree, caregivers with some college education or college degree were less likely to provide whole milk ( 9 percent and 13 percent, respectively) and more likely to provide lower-fat milk to their children. Children with older caregivers were significantly less likely to consume whole milk and more likely to consume lower-fat milk. Compared to children with white caregivers, children with black caregivers were 14 percent more likely to drink whole milk and 10 percent and 3.8 percent less likely to drink reduced-fat and lowfat/slim milks, respectively.

Tables 7, 8, and 9 report the marginal effects for frequencies of $100 \%$ juices, sugar- and artificially sweetened beverages consumed by Texas WIC children. Explanatory variables had different effects on frequencies of consumption of the three beverages. For example, higher education of caregivers had a positive and significant effect on higher frequencies of consumption of $100 \%$ juices and low frequencies of consumption of sugar- and artificially sweetened beverage, but negative and significant effect on higher frequencies of consumption of sugar-and artificially sweetened beverages. The probability of consuming $100 \%$ juices and artificially sweetened beverages more frequently decreased, but the probability of consuming sugar-sweetened beverages more frequently increased after the changes in WIC compared to the period before. The presence of other WIC children in the household had a positive and significant effect on frequencies of consumption of both sugarand artificially sweetened beverages, but there was no significant effect on frequencies of $100 \%$ juice consumption. No significant child-age effect was observed on frequency of $100 \%$ juices and sugar- and artificially sweetened beverage consumption.

\section{Conclusions}

In 2009, WIC food package revisions were implemented to reflect new dietary recommendations and the changing WIC population, to promote healthy food choices and consumption, and to address the problem of overweight/obesity of program participants. This study analyzed the effect of WIC food package changes on the amount and the type of fluid milk and frequencies of other beverages consumed by Texas WIC children ages two through four.

Our findings suggest that the new food packages that restrict purchases of whole milk and reduce the amount of milk provided by WIC had an impact on the type and amount of milk consumed by Texas WIC children in the intended direction. A significant decrease in the amount of whole milk consumed after the WIC revision was observed, and this decrease was partially offset by an increase in the amount of reduced- and low-fat/skim milk consumed by WIC children. Existing studies using data from different states and ethnic groups found similar results, thereby giving us more confidence that the revisions in the WIC food packages significantly affected WIC participants' consumption, especially of milk. 
Table 7. Marginal Effects of Ordered Probit Model for 100\% Juices ${ }^{\mathrm{a}}$ Consumed by Texas WIC Children Ages $2-4$.

\begin{tabular}{|c|c|c|c|c|c|c|c|c|}
\hline & \multicolumn{2}{|c|}{ Never } & \multicolumn{2}{|c|}{ 1-2 times/week } & \multicolumn{2}{|c|}{ 4-6 times/week } & \multicolumn{2}{|c|}{1 or more times/day } \\
\hline & ME & Std & ME & Std & ME & Std & ME & Std \\
\hline Female & 0.001 & 0.002 & 0.004 & 0.010 & 0.001 & 0.004 & -0.012 & 0.000 \\
\hline Three years old & $0.004^{*}$ & 0.002 & $0.021^{*}$ & 0.012 & $0.007^{*}$ & 0.004 & -0.031 & 0.001 \\
\hline Four years old & 0.001 & 0.003 & 0.005 & 0.013 & 0.002 & 0.005 & 0.001 & 0.001 \\
\hline High school or GED & 0.004 & 0.003 & 0.019 & 0.013 & 0.006 & 0.004 & 0.001 & 0.001 \\
\hline Some college & 0.001 & 0.003 & 0.007 & 0.014 & 0.002 & 0.005 & 0.000 & 0.001 \\
\hline College or Graduate & $0.017^{* * *}$ & 0.007 & $-0.084^{* * *}$ & 0.033 & $0.028^{* * *}$ & 0.011 & $0.024^{* *}$ & 0.002 \\
\hline Employed full time & $0.005^{* *}$ & 0.003 & $-0.025^{* *}$ & 0.013 & $0.008^{* *}$ & 0.004 & $0.001^{*}$ & 0.001 \\
\hline Employed part time & -0.003 & 0.003 & 0.016 & 0.015 & -0.005 & 0.005 & -0.001 & 0.001 \\
\hline Hispanic & 0.003 & 0.003 & -0.016 & 0.016 & 0.005 & 0.006 & 0.001 & 0.001 \\
\hline Black & $-0.007^{*}$ & 0.003 & -0.002 & 0.021 & -0.011 & 0.007 & -0.002 & 0.001 \\
\hline Other race & -0.006 & 0.006 & 0.009 & 0.028 & -0.010 & 0.010 & -0.001 & 0.001 \\
\hline Speaks English & 0.002 & 0.003 & 0.011 & 0.015 & 0.004 & 0.005 & 0.001 & 0.001 \\
\hline Speaks Spanish & 0.001 & 0.003 & 0.003 & 0.014 & 0.001 & 0.005 & 0.000 & 0.001 \\
\hline Speaks other languages & $0.043^{* * *}$ & 0.014 & $0.012^{* * *}$ & 0.064 & $-0.072^{* * *}$ & 0.022 & $0.010^{* *}$ & 0.005 \\
\hline Caregiver's age & 0.000 & 0.000 & -0.001 & 0.001 & 0.000 & 0.000 & 0.000 & 0.000 \\
\hline Urban & 0.000 & 0.002 & 0.002 & 0.013 & 0.001 & 0.000 & 0.000 & 0.021 \\
\hline Border region & 0.002 & 0.003 & 0.009 & 0.141 & 0.003 & 0.005 & 0.000 & 0.022 \\
\hline Presence of other WIC children & 0.012 & 0.002 & -0.010 & 0.011 & -0.003 & 0.004 & -0.001 & 0.001 \\
\hline After change in WIC & $0.027^{* * *}$ & 0.002 & $-0.013^{*}$ & 0.010 & $-0.011^{* * *}$ & 0.004 & $-0.002^{* *}$ & 0.001 \\
\hline
\end{tabular}

ME-marginal effect.

Std.- -standard deviation associated with the marginal effect.

$* * * * *$, and * represent significance at $1 \%, 5 \%$, and $10 \%$ levels, respectively.

${ }^{\text {a Here }} 100 \%$ juices include orange, apple, and tomato varieties. 
Table 8. Marginal Effects of Ordered Probit Model for Sugar-sweetened ${ }^{\mathrm{a}}$ Beverages Consumed by Texas WIC Children Ages 2-4.

\begin{tabular}{|c|c|c|c|c|c|c|c|c|}
\hline & \multicolumn{2}{|c|}{ Never } & \multicolumn{2}{|c|}{ 1-2 times/week } & \multicolumn{2}{|c|}{ 4-6 times/week } & \multicolumn{2}{|c|}{1 or more time/day } \\
\hline & ME & Std & ME & Std & ME & Std & ME & Std \\
\hline Female & -0.006 & 0.014 & -0.001 & 0.002 & 0.001 & 0.002 & 0.001 & 0.011 \\
\hline Three years old & -0.003 & 0.016 & 0.000 & 0.002 & 0.000 & 0.002 & 0.001 & 0.013 \\
\hline Four years old & -0.014 & 0.018 & -0.002 & 0.003 & 0.002 & 0.002 & 0.013 & 0.015 \\
\hline High school or GED & 0.023 & 0.017 & 0.013 & 0.003 & -0.013 & 0.002 & -0.025 & 0.014 \\
\hline Some college & $0.026^{* * *}$ & 0.009 & $0.009^{* * *}$ & 0.003 & $-0.017^{* * *}$ & 0.002 & $-0.015^{* * *}$ & 0.016 \\
\hline College or Graduate & $0.073^{* * *}$ & 0.046 & $0.025^{* * *}$ & 0.008 & $-0.050^{* * *}$ & 0.005 & $-0.049^{* * *}$ & 0.037 \\
\hline Employed full time & -0.023 & 0.018 & -0.003 & 0.003 & 0.023 & 0.022 & 0.005 & 0.015 \\
\hline Employed part time & $-0.028^{*}$ & 0.020 & $-0.005^{*}$ & 0.003 & $0.014^{*}$ & 0.002 & $0.018^{*}$ & 0.016 \\
\hline Hispanic & $0.039^{* * *}$ & 0.022 & $0.008^{* * *}$ & 0.003 & $-0.037^{* * *}$ & 0.003 & $-0.013^{* * *}$ & 0.018 \\
\hline Black & $-0.066^{* *}$ & 0.029 & $-0.009 * *$ & 0.004 & $0.027^{* *}$ & 0.003 & $0.035^{* *}$ & 0.024 \\
\hline Other race & -0.001 & 0.038 & 0.000 & 0.006 & 0.000 & 0.004 & 0.000 & 0.031 \\
\hline Speaks English & 0.015 & 0.020 & 0.002 & 0.003 & -0.002 & 0.002 & -0.003 & 0.016 \\
\hline Speaks Spanish & $0.051^{* * *}$ & 0.020 & $0.007^{* * *}$ & 0.003 & $-0.026^{* * *}$ & 0.002 & $-0.031^{* * *}$ & 0.016 \\
\hline Speaks other languages & $0.029^{* * *}$ & 0.094 & $0.033^{* *}$ & 0.014 & $-0.026^{* *}$ & 0.011 & $-0.032^{* *}$ & 0.076 \\
\hline Caregiver's age & $0.003^{* * *}$ & 0.001 & $0.000^{* * *}$ & 0.000 & $0.000^{* * *}$ & 0.000 & $-0.001^{* * *}$ & 0.001 \\
\hline Urban & $0.035^{* *}$ & 0.018 & $0.005^{*}$ & 0.003 & $-0.024^{* *}$ & 0.002 & $-0.018^{* *}$ & 0.014 \\
\hline Border region & $-0.038^{* *}$ & 0.019 & $-0.005^{*}$ & 0.003 & $0.014^{*}$ & 0.002 & $0.029^{* *}$ & 0.016 \\
\hline Presence of other WIC children & $-0.036^{*}$ & 0.015 & $0.004^{*}$ & 0.002 & $0.013^{*}$ & 0.002 & $0.016^{*}$ & 0.003 \\
\hline After change in WIC & $-0.027^{* *}$ & 0.014 & $-0.004^{*}$ & 0.002 & $0.013^{*}$ & 0.002 & $0.016^{* *}$ & 0.011 \\
\hline
\end{tabular}

ME-marginal effect.

Std.-standard deviation associated with the marginal effect

$* * * * *$, and ${ }^{*}$ represent significance at $1 \%, 5 \%$, and $10 \%$ levels, respectively.

${ }^{a}$ Sugar-sweetened beverages include juice drinks, Kool-Aid, soda, cola, sports drinks, and sugar-sweetened tea. The results are for the aggregate of all sugarsweetened beverages. 
Table 9. Marginal Effects of Ordered Probit Model for Artificially Sweetened ${ }^{\mathrm{a}}$ Beverages Consumed by Texas WIC Children Ages 2-4.

\begin{tabular}{|c|c|c|c|c|c|c|c|c|}
\hline & \multicolumn{2}{|c|}{ Never } & \multicolumn{2}{|c|}{ 1-2 times/week } & \multicolumn{2}{|c|}{ 4-6 times/week } & \multicolumn{2}{|c|}{1 or more times/day } \\
\hline & ME & Std & ME & Std & ME & Std & ME & Std \\
\hline Female & 0.007 & 0.017 & -0.001 & 0.002 & 0.000 & 0.001 & -0.001 & 0.012 \\
\hline Three years old & 0.003 & 0.020 & 0.000 & 0.003 & 0.000 & 0.001 & 0.000 & 0.014 \\
\hline Four years old & -0.018 & 0.023 & 0.003 & 0.003 & 0.001 & 0.001 & 0.002 & 0.016 \\
\hline High school or GED & $0.040^{* *}$ & 0.021 & $-0.016^{*}$ & 0.013 & $-0.002^{*}$ & 0.001 & $-0.014^{* *}$ & 0.015 \\
\hline Some college & $0.045^{* * *}$ & 0.024 & $-0.010^{* * *}$ & 0.003 & $-0.015^{* * *}$ & 0.012 & $-0.007^{* * *}$ & 0.017 \\
\hline College or Graduate & $0.076^{* * *}$ & 0.060 & $-0.025^{* * *}$ & 0.009 & $-0.021^{* * *}$ & 0.004 & $-0.018^{* * *}$ & 0.042 \\
\hline Employed full time & -0.010 & 0.022 & 0.001 & 0.003 & 0.001 & 0.001 & 0.001 & 0.016 \\
\hline Employed part time & $-0.055^{* *}$ & 0.025 & $0.008^{* *}$ & 0.004 & $0.023^{* *}$ & 0.002 & $0.025^{* *}$ & 0.017 \\
\hline Hispanic & 0.037 & 0.027 & -0.005 & 0.024 & -0.022 & 0.002 & -0.014 & 0.019 \\
\hline Black & $-0.080^{* *}$ & 0.036 & $0.011^{* *}$ & 0.005 & $0.015^{* *}$ & 0.002 & $0.058^{* *}$ & 0.025 \\
\hline Other race & 0.001 & 0.048 & 0.000 & 0.007 & 0.000 & 0.003 & 0.000 & 0.033 \\
\hline Speaks English & $0.052^{* *}$ & 0.025 & $-0.017^{* *}$ & 0.004 & $-0.013^{* *}$ & 0.002 & $-0.025^{* *}$ & 0.017 \\
\hline Speaks Spanish & $0.053^{* * *}$ & 0.024 & $-0.017^{* * *}$ & 0.003 & $-0.013^{* * *}$ & 0.002 & $-0.015^{* * *}$ & 0.017 \\
\hline Speaks other languages & $0.063^{* *}$ & 0.048 & $-0.031^{* * *}$ & 0.017 & $-0.014^{* *}$ & 0.007 & $-0.022^{* *}$ & 0.083 \\
\hline Caregiver's age & 0.001 & 0.001 & 0.000 & 0.000 & 0.000 & 0.000 & 0.000 & 0.001 \\
\hline Urban & 0.010 & 0.022 & -0.001 & 0.003 & -0.001 & 0.002 & -0.001 & 0.015 \\
\hline Border region & -0.021 & 0.024 & 0.003 & 0.003 & 0.001 & 0.001 & 0.002 & 0.017 \\
\hline Presence of other WIC children & $-0.034^{*}$ & 0.018 & $0.005^{*}$ & 0.003 & $0.012^{*}$ & 0.011 & $0.013^{*}$ & 0.012 \\
\hline After change in WIC & 0.013 & 0.017 & -0.002 & 0.002 & -0.008 & 0.001 & -0.001 & 0.012 \\
\hline
\end{tabular}

ME-marginal effect.

Std.- -standard deviation associated with the marginal effect.

$* * * * *$, and $*$ represent significance at $1 \%, 5 \%$, and $10 \%$ levels, respectively.

${ }^{a}$ Artificially sweetened beverages include diet soda, diet cola, and Crystal Light. The results are for the aggregate of all artificially sweetened beverages. 
The Dietary Guidelines for Americans (USDA 2010) recommend consuming two to two and a half cups of milk per day for children ages two through four years. Although the amount of milk consumed by WIC children in our sample decreased by 11 percent from before to after the WIC revisions, the average amount of milk consumed per day meets the recommendations for milk, both before and after the changes in regulations.

With respect to consumption of beverages other than milk, we found that, in general, $100 \%$ juices were consumed more frequently per day compared to sugar- and artificially sweetened beverages. The explanatory variables used in the analysis had different effects on frequencies of consumption of $100 \%$ juices, and sugar- and artificially sweetened beverages, suggesting that caregivers treat these beverages differently and have unique health and nutrition perceptions for each of them. Munsell et al. (2016) found that almost all parents in their sample and 82 percent of parents of preschoolers provided sugary drinks to their children, and many believed that some sugary drinks such as flavored waters, fruit drinks, and sport drinks are healthy options for children.

The findings of this research should be interpreted with caution due to several limitations. First, we conducted a secondary analysis of the existing data that provide information on self-reported beverage consumption. The amount of beverages consumed, except for milk, was not available, along with some of the other variables, such as household size and income. In addition, frequency of beverages consumed does not necessarily translate into amount of beverages consumed. It is possible that children consumed smaller quantities more frequently or vice versa. Second, we did not have information on the amounts of other foods consumed and not enough information to analyze whether or not WIC participants compensated with other foods. Third, although the data were collected through state WIC agencies, we cannot comment about the representativeness of our sample of Texas WIC children ages two through four. Lastly, the study examined beverages consumed by WIC-participating children and did not address the supply side - specifically food availability and selection options. However, the availability and ease of access to beverages considered in this study might not be an issue. Deviney et al. (2013) reported that not all Texans have access or can afford to purchase healthy foods such as fruits and vegetables, but a far greater percentage has access to high-caloric, emptynutrient foods and drinks.

Although the data were collected through WIC state agencies, and we have data from actual WIC participants, the findings of this research cannot be generalized to other states. Our sample is limited to only Texas and to WICparticipating children who are mostly Hispanic. Furthermore, our findings indicate that most children switched from whole milk to $2 \%$ milk, so the findings cannot be generalized to states that (a) did not allow $2 \%$ milk after the WIC food package changes, or (b) states that did not allow the whole milk before the WIC food package changes. Nonetheless, the findings of this study are consistent with findings from the existing literature that have looked at the impact of the WIC food package revisions on consumption of 
milk and other beverages. By providing a careful analysis of overall beverage choices and consumption patterns of WIC children, the research finds a shift towards healthier consumption patterns and supports the notion that the WIC food package revisions had the anticipated positive effect.

Our results on nutrient intake from milk, both before and after the changes in WIC food packages, provide new and useful information. A significant decrease in the amount of both undesirable and desirable nutrients from milk, except for vitamin A, was observed. This potentially adverse and unexpected effect of the food package revisions can be explained by the decrease in the total amount of milk consumed after the changes in WIC food packages. The percentage of changes in undesirable nutrients from the period before the changes in food packages to after were much higher than the percentage changes in more desirable nutrients. This study looked at the short-term effects of changes in WIC food packages and does not reflect the additional WIC food package changes implemented after 2009, whereby $2 \%$ milk was no longer allowed at all. It is possible that as WIC participants get used to the lower-fat milks, amounts consumed and 'desirable' nutrient intake may increase.

\section{References}

Andreyeva, T. 2012. "Effects of the Revised Food Packages for Women, Infants, and Children (WIC) in Connecticut." Choices ( $3^{\text {rd }}$ Quarter) 27: 1-6.

Andreyeva, T., J. Luedicke, K.E. Henderson, and M.B. Schwartz. 2014. "The Positive Effects of the Revised Milk and Cheese Allowances in the Special Supplemental Nutrition Program for Women, Infants, and Children." Journal of the Academy of Nutrition and Dietetics 114 (4): $622-630$.

Andreyeva, T., J. Luedicke, A.E. Middleton, M.W. Long, and M.B. Schwartz. 2012. "Positive Influence of the Revised Special Supplemental Nutrition Program for Women, Infants, and Children Food Packages on Access to Healthy Foods." Journal of the Academy of Nutrition and Dietetics 112(6): 850-858.

Andreyeva, T., J. Luedicke, A.S. Tripp, and K.E. Henderson. 2013. "Effects of Reduced Juice Allowances in Food Packages for the Women, Infants, and Children Program." Pediatrics 131(5): 919-927.

Ayala, G.X., M.N. Laska, S.N. Zenk, J. Tester, D. Rose, A. Odoms-Young, T. McCoy, J. Gittersohn, G.D. Foster and T. Andreyeva. 2012. "Stocking Characteristics and Perceived Increases in Sales among Small Food Store Managers/Owners Associated with the Introduction of New Food Products Approved by the Special Supplemental Nutrition Program for Women, Infants, and Children." Public Health Nutrition 15(09): 1771-1779.

Black, M.M., K.M. Hurley, S.E. Oberlander, E.R. Hager, A.E. McGill, N.T. White, and A.M. Quigg. 2009. "Participants' Comments on Changes in the Revised Special Supplemental Nutrition Program for Women, Infants, and Children Food Packages: The Maryland Food Preference Study." Journal of the American Dietetic Association 109(1): 116-123.

Burstein, N.R., M.K. Fox, J.B. Hiller, R. Kornfeld, K. Lam, C. Price, and D.T. Rodda. 2000. Profile of WIC Children. Food and Nutrition Service, U.S. Department of Agriculture, Washington, D.C.

Cameron, A.C., and P.K. Trivedi. 2009. Microeconometrics Methods and Applications. Cambridge University Press.

Chiasson, M.A., S.E. Findley, J.P. Sekhobo, R. Scheinmann, L.S. Edmunds, A.S. Faly and N.J. McLeod. 2013. "Changing WIC Changes What Children Eat." Obesity. 21(7): 1423-1429. 
Cole, N. 2001. "The Prevalence of Overweight among WIC Children." Report No. WIC-01-PCM, Food and Nutrition Service, Special Nutrition Programs, U.S. Department of Agriculture, Washington, D.C.

Dennison, B.A., T.A. Erb, and P.L. Jenkins. 2001. "Predictors of Dietary Milk Fat Intake by Preschool Children." Preventive Medicine 33(3): 536-542.

Deviney, F., LeClair, A.V., Lee, J., and Bobbitt, K. 2013. "Investing in Our Future: 2013 State of Texas Children." Texas KIDS COUNT Annual Data Book.

Ettienne-Gittens, R., E.L.J. McKyer, M. Odum, C. Diep, Y. Li, A. Girimaji, and P.S. Murano. 2013. "Rural Versus Urban Texas WIC Participants' Fruits and Vegetable Consumption." American Journal of Heath Behavior 37(1): 129-140.

Greene, W.H. 2008. Econometric Analysis. 6th ed. Upper Saddle River, NJ: Prentice-Hall.

Herman, D.R., G.G. Harrison, A.A. Afifi, and E. Jenks. 2008. "Effect of a Targeted Subsidy on Intake of Fruits and Vegetables among Low-Income Women in the Special Supplemental Nutrition Program for Women, Infants, and Children." American Journal of Public Health 98(1): 98-105.

Hillier, A., J. McLaughlin, C.C. Cannuscio, M. Chilton, S. Krasny and A. Karpyn. 2012. "The Impact of WIC Food Package Changes on Access to Healthful Food in 2 Low-Income Urban Neighborhoods." Journal of Nutrition Education and Behavior 44(3): 210-216.

Institute of Medicine. Food and Nutrition Board, 2006. WIC Food Packages: Time for a Change. Report of the Committee to Review the WIC Food Packages. National Academy Press, Washington, D.C.

Ishdorj, A., and O. Capps. 2013. "The Effect of Revised WIC Food Packages on Native American Children." American Journal of Agricultural Economics 95(5):1266-1272.

Ishdorj, A., H.H. Jensen, and J. Tobias. 2008. "Intra-Household Allocation and Consumption of WIC-Approved Foods: A Bayesian Approach.” Advances in Econometrics 23: 157-182.

Kong, A., A.M. Odoms-Young, L.A. Schiffer, Y. Kim, M.L. Berbaum, S.J. Porter, L.B. Blumstein, S.L. Bess, and M.L. Fitzgiboon. 2014. "The 18-Month Imact of Special Supplemental Nutrition Program for Women, Infants, and Children Food Package Revisions on Diets of Recipient Families." American Journal of Preventative Medicine 46(6): 543-551.

Lin, B.H. 2005. "Nutrition and Health Characteristics of Low-Income Populations: Body Weight Status." Agriculture Information Bulletin 769-3. Economic Research Service, U.S. Department of Agriculture, Washington, D.C.

McKyer, E.L.J., K. Vaughan, P.S. Murano, A. Girimaji, S. Baxter, C. Spaulding, C. Tisone, and M. Ory. 2011. "Development and Testing of the Texas WIC's Food and Nutrition Questionnaire." Texas Public Health Journal 63(1): 46-49.

Munsell, C.R., J.L. Harris, V. Sarda, and M.B. Schwartz. 2016. "Parents' Beliefs about the Healthfulness of Sugary Drink Options: Opportunities to Address Misperceptions." Public Health Nutrition 19(1) 46-54.

Odoms-Young, A.M., A. Kong, L. A. Schiffer, S.J. Porter, L. Blumstein, S. Bess, M.L. Berbaum, and M.L. Fitzgibbon. 2014. "Evaluating the Initial Impact of the Revised Special Supplemental Nutrition Program for Women, Infants, and Children (WIC) food Packages on Dietary Intake and Home Food Availability in African-American and Hispanic Families." Public Health Nutrition 17(01): 83-93.

Oliveira, V., and R. Chandran. 2005. "Children's Consumption of WIC-Approved Foods." Food Assistance and Nutrition Research Report 44, Economic Research Service, U.S. Department of Agriculture, Washington, D.C.

Oliveira, V., and C. Gundersen. 2000. "WIC and the Nutrient Intake of Children." Food Assistance and Nutrition Research Report No. 5, Economic Research Service, U.S. Department of Agriculture, Washington, D.C.

Ponza, M., B. Devaney, P. Ziegler, K. Reidy, and C. Squatrito. 2004. "Nutrient Intakes and Food Choices of Infants and Toddlers Participating in WIC." Journal of the American Dietetic Association 104(1 Suppl 1): 71-79. 
Rose, D., J.P. Habicht, and B. Devaney. 1998. "Household Participation in the Food Stamp and WIC Programs Increases the Nutrient Intakes of Preschool Children." Journal of Nutrition 128(3): 548-555.

Siega-Riz, A.M., S. Kranz, D. Blanchette, P.S. Haines, D.K. Guilkey, and B.M. Popkin. 2004. "The Effect of Participation in the WIC Program on Preschoolers' Diets." Journal of Pediatrics 144(2): 229-234.

U.S. Department of Agriculture. Food and Nutrition Service. 2007. Special Supplemental Nutrition Program for Women, Infants and Children (WIC): Revisions in the WIC Food Packages. Federal Register, 72: 68966-69032.

Food and Nutrition Service. 2011. "WIC Participant and Program Characteristics 2010." WIC1-PC, FNS, U.S. Department of Agriculture

U.S. Department of Agriculture and U.S. Department of Health and Human Services. 2011. Dietary Guidelines for Americans, 2010. 7th Edition, Washington, DC: U.S. Government Printing Office.

U.S. Department of Agriculture, Agricultural Research Service, Nutrient Data Laboratory. USDA National Nutrient Database for Standard Reference, Release 28. Version Current: September 2015, slightly revised May 2016.

Ver Ploeg, M. 2009. "WIC and the Battle Against Childhood Overweight." Economic Research Service, U.S. Department of Agriculture, Washington, D.C.

Whaley, S.E., L.D. Ritchie, P. Spector, and J. Gomez. 2012. "Revised WIC Food Package Improves Diets of WIC Families." Journal of Nutrition Education and Behavior 44(3): 204-209.

Yen, S.T. 2010. "The Effects of SNAP and WIC Programs on Nutrient Intakes of Children." Food Policy 35(6): 576-583.

Zenk, S.N., A. Odoms-Young, L. M. Powell, R.T. Campbell, D. Block, N. Chavez, R. C. Krauss, S. Strode and J. Armbruster. 2012. "Fruit and Vegetable Availability and Selection Federal Food Package Revisions, 2009." American Journal of Preventative Medicine 43 (4): 423-428. 